\title{
Development And Application Of Mechanized Control Equipment For Roadway Floor Heave In Coalmine
}

\author{
Youzhen Zhang, Junjie Shao, Pan Chen, Xutao Li, Zhitao Kan \\ Xi'an Research Institute of China Coal Technology \& Engineering Group Corp. Xi'an, 710077, China
}

Keywords: mechanical engineering; coalmine roadway; floor heave control; mechanized construction

\begin{abstract}
The deformation control of surrounding rocks is one of the key problems in deep mining, especially floor heave control. In view of coal mine disaster caused by roadway surrounding rock under complex geological conditions, the lack of special mechanical control technology and equipment, the construction characteristics of the surrounding rock maintenance technology is analyzed, the roadway multifunction repair machine and the floor anchor drill rig are developed and applied at Binchang Coalmine of shaanxi province. The field test results show that the set of technical equipment can effectively improve the mechanization and technology level of the coal mine roadway surrounding rock control. The study provides a reliable guarantee for the safe and efficient production, and has significance in the downsizing for efficiency in coalmines.
\end{abstract}

\section{Introduction}

As the basic unit of the coal mine production system, the safe and reliable roadway support is fundamental to ensuring the efficient production of mine. In recent years, as a result of highly intense mining and the increase of the mining depth, the deformation control of surrounding rock is increasingly difficult. The problem of roadway floor heave is the most prominent. A large amount of practical measurement shows that the amount of roadway floor heave is close to $70 \%$ of the amount of roof-to-floor convergence in lack of control of roadway floor ${ }^{[1-4]}$. Since the floor is the basis of roadway, severe floor heave can lead to the instability of roadway; bring negative impact on ventilation and underground transportation. Even the whole coal mine production safety is seriously affected. Therefore, the prevention and control of roadway floor heave has become one of the major problems in surrounding rock control maintenance in coalmines.

In recent years, many experts and scholars have carried on the related discussion and research in floor heave control ${ }^{[5-8]}$. At present, three methods can be applied to the control of the floor heave of roadway, which includes improving the floor mechanical environment, optimizing the floor lithology and improving the floor supporting strength. The specific methods of floor pressure relief include: cutting floor groove, drilling, and blasting, cutting unloading roadway. The specific methods of floor supporting include: floor anchor, floor grouting, closed support, as well as a variety of joint protectors. Among them, the method of grouting with anchor is more applied to the floor heave control because of the control effect and high operability. In engineering practice, the construction cannot be carried out without the highly efficient, reliable and special mechanical floor heave control technology and equipment. At present, the control construction method in the most frequent use is still the artificial floor heave remove with a handheld jumbolter, which is usually time-consuming, of low security and efficiency. The other method is the use of the nodedicated equipment such as excavators, loaders. This method which should turn to too much corollary equipment is only applied roadway with big cross section and small amount of floor heave. Thus, this method with low specialization and adaptability cannot meet the needs of the conventional fast control of roadway.

Combining the geological conditions of the coal mine with roadway floor control construction characteristics, the roadway multi-function repair machine and floor anchor rig are developed. They both have characteristics of compact structure, convenient movement and high adaptability. The innovative design of the whole machine structure, working mechanism and hydraulic system has realized safe and efficient mechanized construction in the roadway floor heave control of coal mine. Simultaneously, the method of floor grouting with anchor used to control the floor heave, with good control effect, high operability and excellent application effect, provides reference for the similar mine floor heave control.

\section{The maintenance technology of roadway surrounding rock}

The recovery technology of roadway surrounding rock is based on the original roadway support. According to new pressure and deformation characteristics of roadway, the part of the support is reformed and increased, which can make it not damaged under mining influence. In other situations, the surrounding rock is damaged but still safe through a small amount of maintenance. The basic starting point of the roadway maintenance is built on the principles of roadway surrounding rock control, which include reducing the stress of surrounding rock of roadway, increasing strength of surrounding rock, and selecting reasonable supporting control approach. As is shown in figure 1, roadway cross section 
recovery is the primary task in the surrounding rock mechanized construction flow. In view of the different types of roadway, the implementation of the maintenance roadway construction process is different, and the differences in control measures and cost are large. The development roadway often needs to take grouting and high pre-stress anchor bolt technology to reinforce the construction. The mining preparation roadway that includes preparation roadway and mining roadway can be put into use directly after removing floor heave.

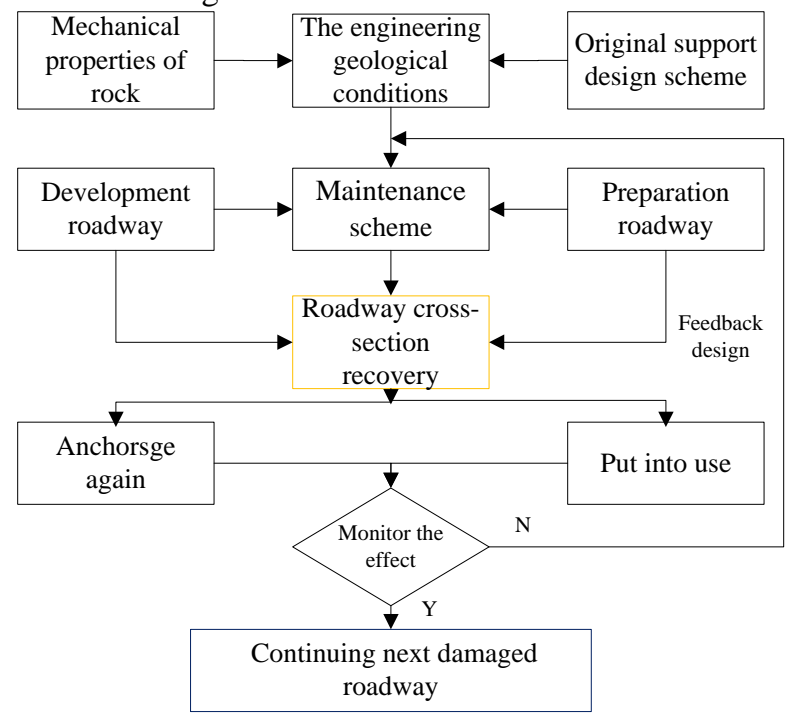

Figure 1: the roadway surrounding rock mechanized maintenance technology flow

Coal mine roadway floor generally doesn't have any support. Thus, floor is the starting point of instability and failure of roadway. The floor heave is a major way of surrounding rock deformation and failure, which is caused by the change in stress state of the surrounding rock in excavation or mining and the change in its properties in the maintenance. The pattern of floor heave makes the roof and floor and roadside mass deform and move to the centre of roadway, floor uplift. It prevalently occurs in floor strata with low intensity or roadway easily affected by mining. Therefore, floor mechanized construction is the core of the roadway surrounding rock mechanized maintenance tasks.

The roadway surrounding rock is a compound structure consisting of roof, floor and roadsides. The stress state of roadway floor is changed by roadway floor removing, which further causes load-bearing ring to move to the deep, roadway roof and two roadsides to be damaged more seriously. The roof and two roadsides should be reinforced before roadway floor removing. The roadway floor removing should be carried out mainly within the scope of the load-bearing ring, and mustn't excavate the ring which is beneficial to the global stability of the roadway. Through grouting and high pre-stress anchor bolt technology, the floor lithology and mechanics environment is improved. The floor pressure arch structure is formed, which can shield the destruction as a result of the roadway floor load effect and can effectively solve serious floor deformation in the complicated geological conditions.

\section{Development of mechanized control equipment}

\subsection{The multifunctional coalmine roadway repair machine}

Based on in-depth research in complex geological conditions in coal mine roadway and related equipments, the WPZ$55 / 50 \mathrm{~L}$ roadway repair machine is developed. It is the equipment for control of roadway floor in coalmine, integrating cutting, digging, transportation and loading. It is characterized by advantages such as narrow frame, high automation, advanced fluid control performance, easy move and so on, greatly decreasing labor intensity, increasing work efficiency and improving working environment.

The roadway repair machine consists of six assembly parts. They are working device, cab, scraper transport device, caterpillar body, hydraulic pump station and accessory, as is shown in figure 2 . The main technical parameters are shown in table 1.A friction type crawler chassis is designed to improve traffic capacity under the deformation condition of roadway. The fan cooler can avoid repeated impact of cooling water on the swelling roadway floor. High pressure water pump can avoid the dust pollution in construction. Automatic roll cable device can ensure dragging cable in random and automatic way when the repair machine movements in construction. The innovative design and functional integration of multifunctional coalmine roadway repair machine realize fast mechanical construction of the control of floor heave of roadway.

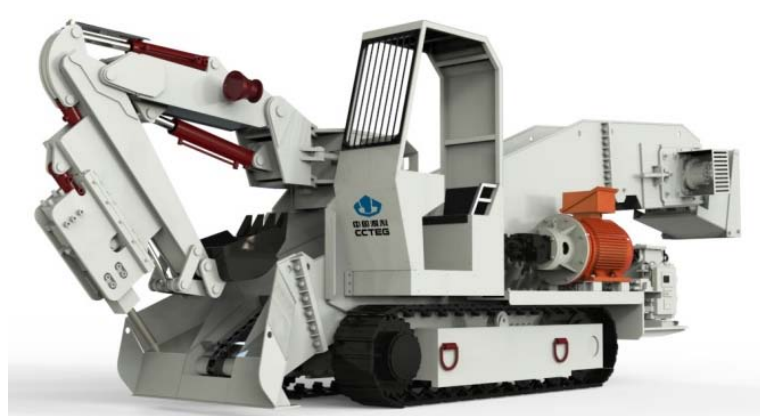

Figure 2: the roadway repair machine general view

Table I: The roadway repair $m$ achine main te chnical parameters

\begin{tabular}{|l|l|l|}
\hline Assembly part & Subject & Parameter \\
\hline \multirow{4}{*}{ Working device } & Loading capacity & $50 \mathrm{~m}^{3} / \mathrm{h}$ \\
\cline { 2 - 3 } & Excavating width & $5 \mathrm{~m}$ \\
\cline { 2 - 3 } & Excavating height m & $3.5 \mathrm{~m}$ \\
\cline { 2 - 3 } & $\begin{array}{l}\text { Quartering hammer } \\
\text { frequency }\end{array}$ & $10 \mathrm{~Hz}$ \\
\hline \multirow{2}{*}{$\begin{array}{l}\text { Scraper transport } \\
\text { device }\end{array}$} & Scraper chain velocity & $0.7 \mathrm{~m} / \mathrm{s}$ \\
\cline { 2 - 3 } & Unloading height & $1.4-1.7 \mathrm{~m}$ \\
\hline \multirow{2}{*}{$\begin{array}{l}\text { Hydraulic pump } \\
\text { station }\end{array}$} & Motor power & $55 \mathrm{~kW}$ \\
\cline { 2 - 3 } & Rated voltage & $660 / 1140 \mathrm{~V}$ \\
\hline Complete & Dimension $(\mathrm{L} \times \mathrm{W} \times \mathrm{H})$ & $7.5 \times 1.6 \times 2.0 \mathrm{~m}$ \\
\cline { 2 - 3 } machine & Weight & $1100 \mathrm{~kg}$ \\
\hline
\end{tabular}




\subsection{The floor anchor drill rig}

ZDY-750L type coal mine roadway crawler mounted floor anchor drill rig is only $1 \mathrm{~m}$ in width. It is mainly used in special equipment when construction is carried out in coal mine roadway floor anchor hole and grouting hole, which can greatly enhance the mechanization level of roadway floor control construction. The floor anchor drill rig has a lot of advantages that are respectively narrow body, easy dismounting, high mechanization degree, advanced fluid control performance technology, strong technical adaptability, and convenience in moving. The floor anchor drill rig can realize fast mechanical drilling construction on floor, two roadsides and roof. The drilling construction can ensure high efficiency, greatly reduce the labor intensity of workers, and effectively improve the working environment. According to field test, bench test and field industrial test, the floor anchor drill rig meets the design requirements and the demands for practical production.

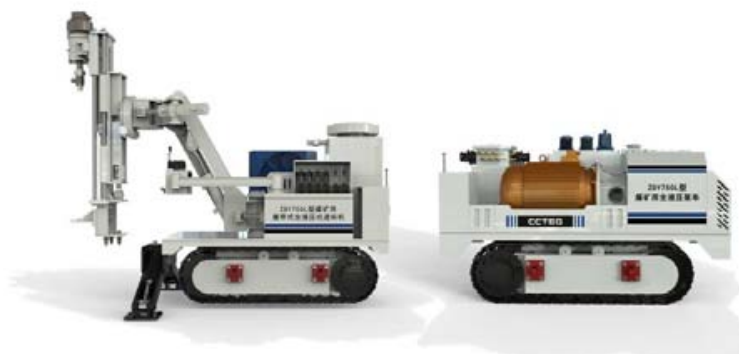

Figure 3: the floor anchor drill rig general view

As is shown in figure 3, ZDY-750L type splitting crawler mounted floor anchor drill rig consists of drill rig and pump truck. There are four components of a drill rig: drill unit, control panel, dust removal unit, crawler parts. The control panel can be put on the drill unit during transportation. The pump truck is made up of motor, oil tank, pump station and other parts. Two parts are connected by the high-pressure hose. The floor anchor drill rig is characterized by compact structure and high reliability. The main technical parameters are shown in table 2 .

Table II: The floor anchor drill rig main technical parameters

\begin{tabular}{|l|l|l|}
\hline Assembly part & Subject & Parameter \\
\hline \multirow{4}{*}{ Working device } & Rated torque & $750 \sim 650 \mathrm{Nm}$ \\
\cline { 2 - 3 } & Rated rotate speed & $200 \sim 240 \mathrm{r} / \mathrm{min}$ \\
\cline { 2 - 3 } & Max feeding force & $12 \mathrm{kN}$ \\
\cline { 2 - 3 } & Feeding speed & $2 \mathrm{~m} / \mathrm{min}$ \\
\hline \multirow{2}{*}{$\begin{array}{l}\text { Hydraulic } \\
\text { pump station }\end{array}$} & Motor power & $45 \mathrm{~kW}$ \\
\cline { 2 - 3 } $\begin{array}{l}\text { Complete } \\
\text { machine }\end{array}$ & $\begin{array}{l}\text { Rated voltage } \\
(\mathrm{L} \times \mathrm{W} \times \mathrm{H})\end{array}$ & $660 / 1140 \mathrm{~V}$ \\
\cline { 2 - 3 } & Weight & $4000 \mathrm{~kg}$ \\
\hline
\end{tabular}

The type of oil cylinder-chain doubled distance and speed is applied to drill rig feed machinery. It is more smooth and efficient. The integration negative pressure dust removal system can reduce pollution and improve the working environment. The hydraulic system is mainly composed of crawler walking circuits, rotary circuit, feeding circuit and auxiliary functions of circuits. The crawler walking circuit mainly realizes the crawler drill rig's walking, turning and braking. Rotary circuits provide rotary force. With the help of feed force provided by feeding circuit, the composite action of drilling and feeding is implemented. Auxiliary circuit is mainly responsible for drill rig's position adjustment, immobilization, cooling and dust removal function. Combined with the floor anchor drill rig research and development in practice, the general principles of the roadway floor control methods are summarized. Based on that, a floor heave control technology of grouting and high prestress anchor bolt is developed, which is simple in process, convenient to operate, convenient to be realized, low-cost and efficient.

\section{Field applications}

The way of developing with vertical shaft at single level is applied in Binchang coal mine in shaanxi province. The mining field is a Mesozoic Jurassic strata formation buried deep underground for about $510 \sim 510 \mathrm{~m}$. The main return roadway floor in the second mining consists of mudstone and silty mudstone, which, with low strength and joint developed in certain area, easily expanse and frozen in block structure in face of water. Due to undue pressure on No.1402 longwall working face, the roadway with serious floor heave cannot be put into normal use. According to the geological conditions of roadway, the final construction scheme is determined. That is, the roadway repair machine, the floor anchor drill rig and grouting and high pre-stress anchor are used one by one in order to prevent the repeated floor heave. The floor must be shaved below the roadway standard height for about $200 \mathrm{~mm}$ before strengthening. The orbit inside the roadway should be dismantled in segments. Finally the floor should be filled to the standard height with track laid again.

The construction scheme making best use of the bearing capacity of floor strata of roadway and its character of steadiness changes the passive support to active one. Considering the interaction of roadway surrounding, floor and two roadsides can been seen as an integral structure. The arch structure which transfers the floor load to two roadsides and balances the roadsides' load is conductive to the overall stability of the surrounding rock of roadway. The construction scheme of good effect can effectively solve the problem of floor heave of roadway under complex conditions. The scheme is especially suitable for control of floor heave of roadway in coal mine under the condition featured by the high in-situ stress.

(1) Bottom-digging work

The roadway has rectangle section, the size of which is: width $\times$ height $=4600 \mathrm{~mm} \times 3500 \mathrm{~mm}$. The roadway roof is supported with anchor nets and locks. Drains are arranged on the left of roadway repair machine work area, which are used to discharge water on coal mining face. On the right lie a large number of cables. Simultaneously, rails are laid on the right front. Moreover, scraper conveyor installed on the ground is responsible for the transport of the residue after digging bottom. 


\section{(2) Slurry pre-injection}

The rock stratum on the bottom is soft and broken. Slurry preinjection, thus, should be first carried out in order to prevent grouting holes from collapsing and further blocking the cracks for leakage of slurry. In order to solve such problems as small drilling space and difficult deslagging, the test mainly adopts the construction process of rotary drilling, loading /unloading drill pipe while drilling and slagging inside the holes with the help of wind from pipes. To accomplish such a construction technology, $\Phi 56 \mathrm{~mm}$ threewing spiral diamond composite chip drill bits and $\Phi 50$ / 42 wide blade auger are specially designed.

(3) Floor reinforcement

Reinforcement is realized with the help of anchor support and grouting. The anchor cable is $\Phi 22 \mathrm{~mm}, 1 \times 19$ strands of high strength and low relaxation prestressing strand, $5.5 \mathrm{~m}$ in length. As the roadway section is $4.6 \mathrm{~m}$ in width and the ditch with the size of $300 \mathrm{~mm} \times 300 \mathrm{~mm}$ is required on the left, drilling holes are installed with 4 anchor cables with $1.2 \mathrm{~m}$ spaces between them in a row. The space between rows is still $1.2 \mathrm{~m}$. Anchor cable arrangement is shown in Figure 4. In order to better control the floor heave in coal mines, the drill hole in the middle of the tunnel is perpendicular to the floor, and those near two sides are arranged with 15 degrees outside the firm corner.

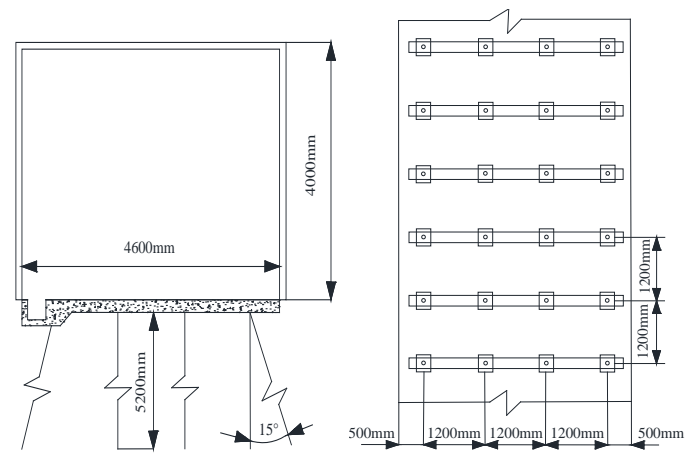

Figure 4: the floor reinforcement construction diagram

\section{Conclusion}

(1) This paper analyzes the technical characteristics of treatment of floor heave in mine roadway, and puts forward the mechanized rehabilitation construction of roadway floor heave is the core task of mechanized control of the surrounding rocks.

(2) According to the underground geological conditions and construction characteristics of coal mines, a new multipurpose mine roadway repair machine and a floor anchor drilling rig have been developed to realize the rapid mechanized treatment.

( 3 ) In the practical application, the use of special equipments and related treatment technologies such as pregrouting, prestressed anchor cable makes good treatment effect achieved, which provides references for control of floor heave in coal mines with similar conditions.

\section{Acknowledgements}

This research was financially supported by the National Natural Science Foundation of China (Grant No. 51275061) and Science and Technology Innovation Foundation of China Coal Technology \& Engineering Group Corp (Grant No. 2014MS038).

\section{References}

[1] He Manchao. "Progress and challenges of soft rock engineering in depth”, Journal of China Coal Society, 39, pp.1409-1417,(2014).

[2] B.Indraratna, J.A. Nemcik. "Floor failure analysis at a longwall mining face based on the multiple sliding block model”, Geotechnical and geological engineering, 18, pp.175-192, (2000).

[3] Yubing Gao, Yanchun Xu, Shiqi Liu. "Mechanism analyses on floor heave and water inrush when rock roadway traversing faults above high-pressure water body ", International Journal of Mining and Mineral Engineering,7,pp.126-138,(2016).

[4] Sun Jin,Wang Liangguo. "Numerical simulation of grooving method for floor heave control in soft rock roadway”, Mining Science and Technology (China), 21, pp.49-56, (2011).

[5] Hua Xinzhu,Li Yingfu. “ Mechanics analysis on floor deformation of gob-side entry retaining and prevention and control of floor heave",Journal of China Coal Society,41,pp.1624-1631,(2016).

[6] Kang Hongpu,Niu Duolong,Zhang Zhen,et al. "Deformation characteristics of surrounding rock and supporting technology of gob-sideentry retaining in deep coal mine", Chinese Journal of Rock Mechanics and Engineering,29,pp.1977-1987, (2010).

[7] Zhang Youzhen. "Analysis on working space and movement trajectory of working mechanism for mine roadway repair machine”, Coal Science and Technology, 43,pp.97-101, (2015).

[8] Yuan Liang, Xue Junhua, Liu Quansheng, et al. "Surrounding rock stability control theory and support technique in deep rock roadway for coal mine”,Journal of China Coal Society,36,pp.535-543,(2011). 